\title{
Syntheses of marine molecules
}

\author{
Julio D. MartIn, Jose M. Palazó, Cirilo Perez, and Jose L. Ravelo \\ Instituto Universitario de QuImica Orgánica, Universidad de La \\ Laguna, and Instituto de Productos Naturales Orgánicos, CSIC, \\ La Laguna, Tenerife, Spain
}

\begin{abstract}
The enantioselective total syntheses of $(-)(E) \gamma-$ bisabolene-8,9-epoxide, (+) (2S,6R)-2-bromo- $\beta$-chamigrene, and $(+) \beta$-chamigrene, important intermediates in the biosynthesis of natural sesquiterpenoids isolated from algae of the genus Laurencia, are described. The compounds are synthesized with regio and stereocontrol by using simple forms of bridged intermediates. This represents a general strategy for the enantioselective construction of spiro|5.5|undecane systems containing a chiral quaternary center. Our recent current progress towards the synthesis of the biologically active $\mathrm{C}_{25}$ tetronic acids isolated from sponges of the genus Ircinia is also described.
\end{abstract}

\section{INTRODUCTION}

Among the halogenated marine natural products, the largest and most varied group is the spirobicarbocyclic chamigrenes obtained from the red algae of the genus Laurencia and their associated herbivores (Ref. 1). It has also been repeatedly postulated, and chemically proven in some cases or simply hypothesized in others, that the variety of carbon skeletons isolated from these algae owe their origin to particular rearrangements of common chamigrene precursors (Ref. 2).

Most of the halogenated chamigranes described up to now from marine algae are derived (Ref. 2) from one of the two chamigrane ions represented by structures I and II. Both types of precursors possess an (8S,9S)-trans-heterosubstituted moiety and a bromine atom at $\mathrm{C} 2$ in opposite absolute configuration to that of the quaternary chiral center at $\mathrm{C} 6$.

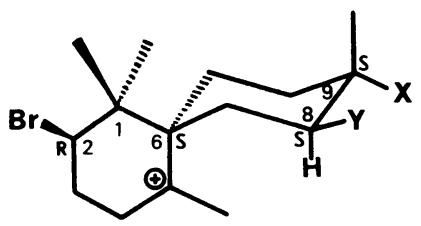

$X_{;} Y=\mathrm{Br}_{;} \mathrm{Cl} ; \mathrm{OH}$

(1)

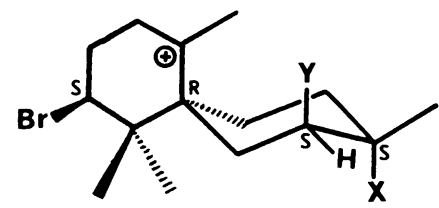

(II)

Spirocycles represent challenging targets in both natural products and theoretical chemistry, and the construction of the quaternary carbon-center remains a fundamental test of synthetic methodology (Ref. 3). Although several successful racemic syntheses (Ref. 4) of the terrestrially found $(-) \alpha-c h a m i-$ grene (1) (Ref. 5), a sesquiterpene that has the spiro|5.5|undecane system as the basic skeleton, have been reported, little is known about the synthesis of the more complex chamigrenes found in marine sources. The reported racemic syntheses (Ref. 6) of the naturally found (2R,6S)-2-bromo- $\alpha$-chamigrene (2) (Ref. 7) gave a diastereoisomeric mixture (Ref. 6a,b) with apparent spectroscopic and chromatographic identity. As a part of our program on the synthesis of intermediates in terpene biogenesis and constituents of marine organisms, we have developed and record herein the first enantioselective synthesis of the L. pacifica (Ref. 8) metabolite (2S,6R)-2-bromo- $\beta$-chamigrene $(3 \mathrm{~b})$, a discussion of which is part of this communication. 


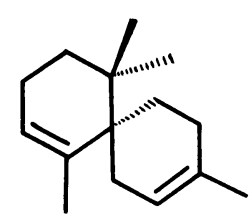

1

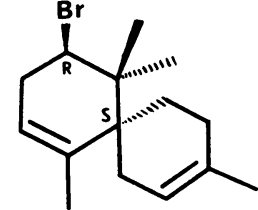

2

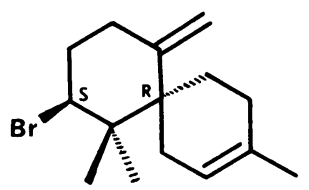

3b

\section{RESULTS AND DISCUSSION}

The approach to the synthesis of polycyclic systems with terpenoid stereochemistry and substitution, by acid-catalyzed cyclization of appropriate polyolefinic substrates, provides not only non-enzymic analogies that mimic biosynthetic processes but also practical synthetic procedures for the stereoselective generation of fused carbocyclic systems. The elegant work undertaken at stanford (Ref. 9, 10) and Harvard (Ref. 11) has allowed the syntheses of steroids and terpenes following the "biochemically patterned" routes. The so-called "biomimetic synthesis" appears to be a reasonable synthetic alternative for polycyclic terpenoids (Ref. 12), although careful choice of starting polyenes and some "non-biomimetic" modifications may be required.

Biogenetic reasoning suggests that most of the brominated terpenoids found in marine sources arise in nature by means of "brominative cyclization" of a polyenic precursor, in which the bromonium ion (or a biological equivalent) serves as the initiating electrophile. The ensuing cyclization, especially its stereochemical outcome, has extensive precedent in the studies of Lewis acid-catalyzed polyolefin cyclizations. Methods based on in vitro polyenic cyclization by direct carbon-bromine bond formation with concomitant ring closure, or the alternative indirect incorporation of bromine to cyclized intermediates, have been employed for the stereospecific synthesis of brominated marine terpenoids. Reagent systems that have been used successfully in this endeavor include N-bromosuccinimide (Ref. 13a,c), bromine in the presence of Lewis acids such as $\mathrm{AlBr}_{3}, \mathrm{SnBr}_{4}$ or silver (I) ion (Ref. 13d,e), 2,4,4,6tetrabromocyclohexa-2,5-diene (TBC) in acidic medium (Ref. 14), and acid- catalyzed cyclization of terminal bromohydrins of polyenes (Ref. 15). Mercuric trifluoroacetate (Ref. 16a-d) or the mercuric trifluoro-methanesulfonate/amine complex (Ref. 16e-f) have also been successfully used in the syntheses of brominated terpenoids.

There are two possible biosynthetic routes from farnesyl pyrophosphate (4) to 2-bromo- $\beta$-chamigrene (3), depending on the order in which the rings are formed (Scheme 1). Cyclization with loss of pyrophosphate gives $\gamma$-bisabolene (5) as an intermediate (route b), while bromonium ion-initiated cyclization gives a brominated monocyclofarnesol pyrophosphate $\preccurlyeq$ as the intermediate (route a, Scheme 1).

Even if it were possible to check the chemical viability of one of the pathways (a or $b$ ) of Scheme 1 , the sense in which the biological transformation occurs could not be affirmed with absolute certainty, and those compounds having a monocyclofarnesane (6) or $\gamma$-bisabolane skeleton ( 5 ) isolated from marine algae (Ref. 1) may well occur by fragmentation of a chamigrene precursor.

\section{Scheme 1}

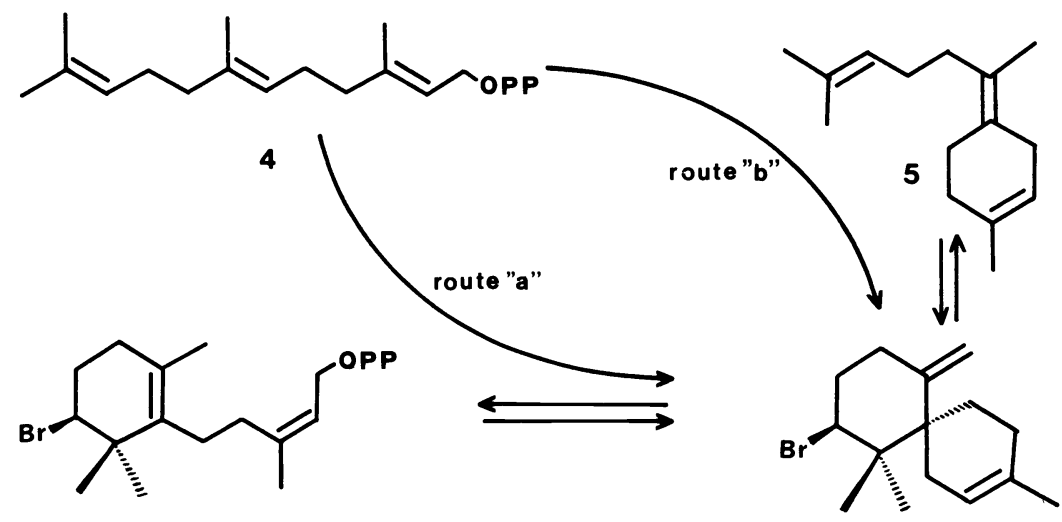




\section{Scheme 2}

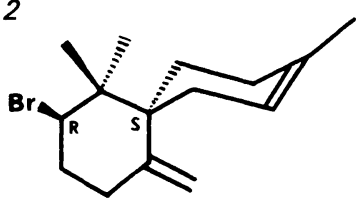

$3 \mathbf{a}$

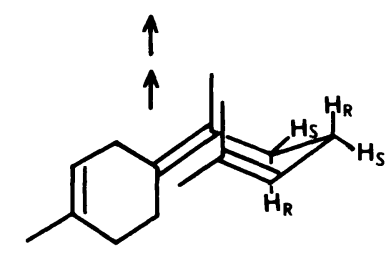

5 a

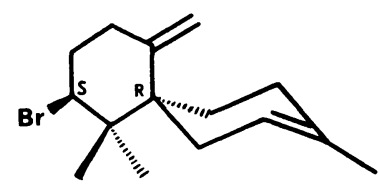

$3 b$<smiles>CC1=CCC(=C(C)C)C(C(C)C)C1</smiles>

5b

It is not our intention to enter into a discussion as to which of the two possible biogenetic pathways is the one that probably occurs in the marine environment, nor do we wish the results of the synthesis reported here to be interpreted in favour of either. Our synthesis was inspired by the biogenetic option shown in pathway b, for the purely synthetic reason that we would be carrying out an enantioselective synthesis through enantiocontrolled bromination, in accordance with scheme 2, which would allow differentiated syntheses to be carried out on bromochamigrenes with the absolute configuration of their chiral centers identical with that of those isolated from the natural marine medium.

The structures of I and II suggested to us a synthesis in which all four chiral centers could be introduced stereospecifically by cyclization of the common diene 7 (Scheme 3), in which the absolute configuration at C 8 and C9 would uniquely determine the remaining two stereocenters. The conformations of 7 required for synchronous brominative cyclization via diastereomeric transition states to give $\&$ and 2 are shown in scheme $\overline{3}$, and the cyclization

\section{Scheme 3}
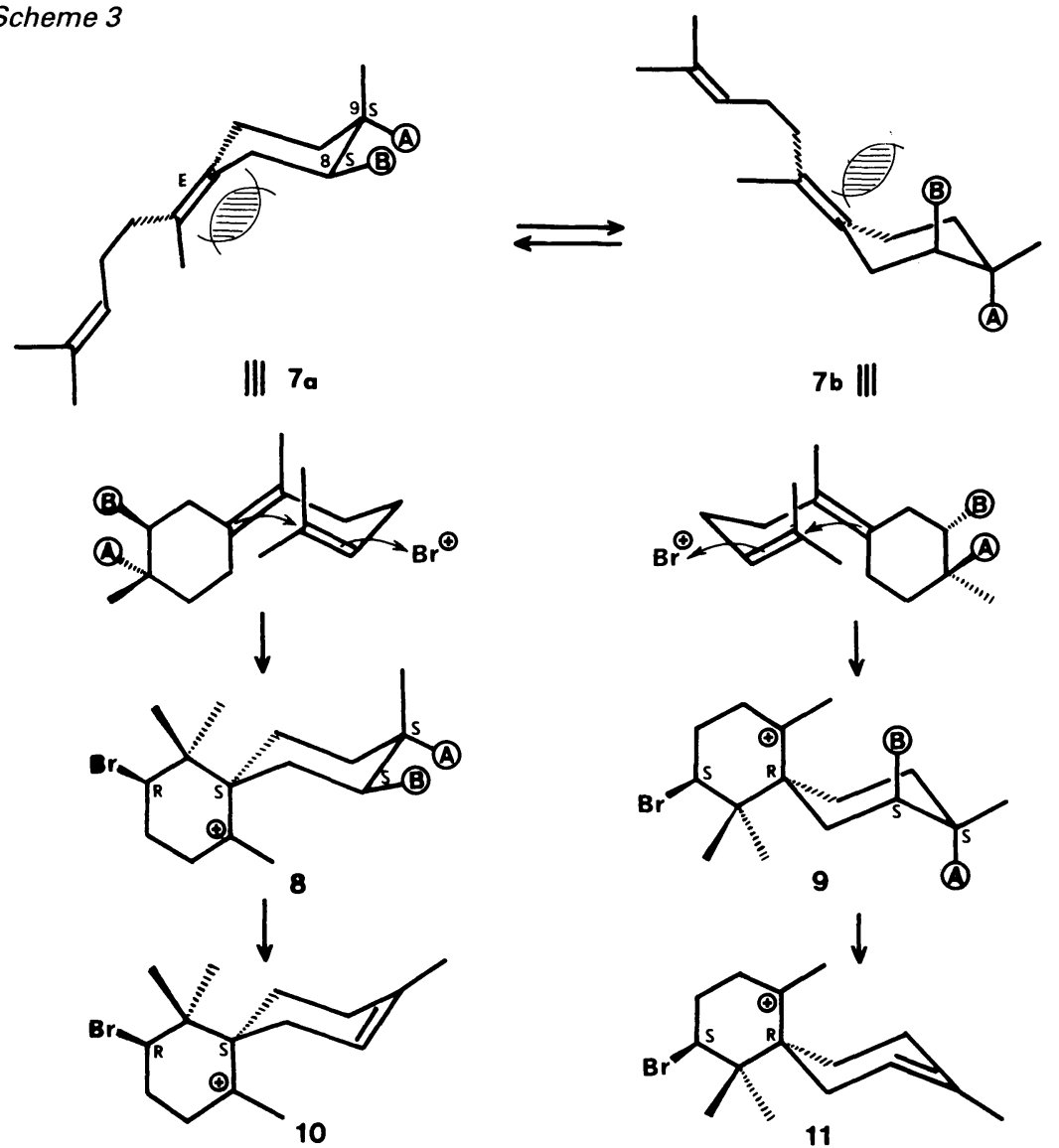

7b III

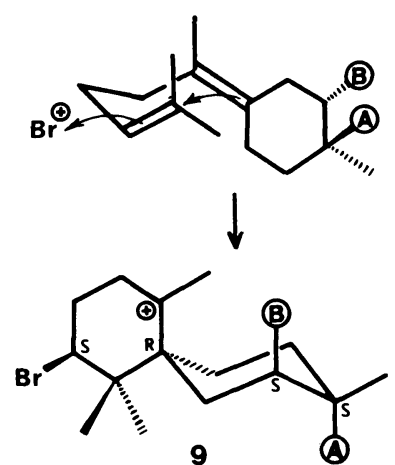

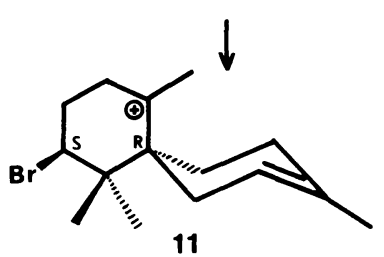


preference will depend on the conformational $7 \mathrm{a}-7 \mathrm{k}$ interconversion and their coiled transition states. The substantial preference observed ( $\operatorname{Ref}$. 17) for six-membered ring formation suggested a highly ordered transition state in which the two methylenes of the chain have adopted a staggered conformation, leading to a chair-like six-membered ring. It should be noted that the diastereomeric transition state to $7 \mathrm{a}$ is $\mathrm{Zl}$, in which the dienic chain is swung across the front face of the cyclohexane ring, rather than the back face. It would be necessary to control the folding of the rapidly coiling side chain in such a way that the desired site was particularly available for reaction. To achieve enantioselectivity, it is necessary to selectively destabilize one of these two transition states.

In the absence of overriding competing steric hindrance, access to closure should be largely restricted to the more convex sides which control the stereochemistry of ring junction. Following a parallel sequence, the (Z)diastereoisomer of $Z$ would give the non-naturally found chamigrane intermediates possessing identical absolute configuration at C2 and C6 : $(2 \mathrm{~S}, 6 \mathrm{~S})$ or $(2 \mathrm{R}, 6 \mathrm{R})$. The olefinic intermediates 10 and 11 may be formed by transelimination of the control elements (A) and (B). Due to the enantiomeric 18 and $t$ t relationship, identical results would be reached starting from the $(8 \mathrm{R}, 9 \mathrm{R})$-enantiomer of 2 .

We have now shown that such is indeed the case. By combining this enantioselective cyclization with our reported method (Ref. 18) for stereocontrolled synthesis of ( $( \pm)(E)-\gamma$-bisabolene-8,9-epoxide (2l) it should be possible to create a variety of diversely substituted chamigrenes of high enantiomeric purity.

\section{SYNTHESIS OF $(-)$ (E)- $\gamma$-BISABOLENE-8,9-EPOXIDE}

We have recently (Ref. 18) published how racemic 8,9-trans-disubstituted (E)and $(z)-\gamma$-bisabolenes are synthesized with regio- and stereocontrol by using simple forms of bridged intermediates (Scheme 4). The control elements (A) and (B) are inherent to the molecular organization of the starting material and are converted to vicinal groupings having defined stereochemistry in the final products. The stereochemistry of the tetrasubstituted olefinic bonds is controlled by bridging delivery from $\mathrm{C} 5$ and $\mathrm{C} 6$ positions.

\section{Scheme 4}<smiles>CC(C)=CCC[C@](C)(O)[C@]1(C)CC=C(C)CC1</smiles>

The synthesis (Scheme 5) was initiated from the ( \pm ) $\beta$-hydroxy acid 13 , available (Ref. 19) on a large scale from 4-methyl-3-cyclohexene carboxýlic acid and 6-methyl-5-hepten-2-one in 85\% yield, followed by fractional recrystallization of the diastereoisomeric mixture. Reaction of the diisopropylamine salt of 13 with iodine in dichloromethane produced the iodolactone 14 (Ref. 20) in 97\% yield. Treatment of 14 in THF with 1.5 equiv of aqueous potassium hydroxide at $0^{\circ} \mathrm{C}$ for $2 \mathrm{~h}$ and isolation of the acidic product provided the unstable epoxy acid 15 in $98 \%$ yield, which without further purification was treated with a catalytic amount of p-toluenesulfonic acid in methylene chloride to produce $16(\mathrm{R}=\mathrm{H})$ in $100 \%$ yield. The sequence $1, \beta$, to 16 ( $\mathrm{R}=\mathrm{H})$ can be carried out easily in the laboratory on a 1-mole scale, and the Intermediates 14 and 15 need not be purified. The $\left(5 S^{*}, 6 R^{*}, 8 R^{*}, 9 R^{*}\right)$ enantiomer $1 \delta_{2}(R=A C)^{2},\{\alpha\}^{-32} .3^{\circ}\left(\mathrm{CHCl}_{3}\right)$ could be obtained readily from the racemic acetoxy-acid by resolution involving recrystallization of the salt 
with quinine from acetone (Ref, 21). Bromination ( $\mathrm{Br}, \mathrm{CCl}_{4}$ ) of the crystalline acetate $16(R=A C)$ gave the dibromo-derivative which was decarboxylated (Ref. 22) by reaction with lead tetraacetate and $\mathrm{N}$-chlorosuccinimide in DMF- HOAC $(5: 1)$ to give $17(\mathrm{R}=\mathrm{H})$ in $86 \%$ yield (10\% of 16 ( $\mathrm{R}=\mathrm{H}$ ) was recovered). The dibromide $1 \lambda(\mathrm{R}=\mathrm{H})$ was then subjected to reductive elimination of bromine by zinc dust (ether-HOAC) to form the chloro ether $18(R=H),\{\alpha\}-31.9^{\circ}$ (c) $\left.0.94, \mathrm{CHCl}_{3}\right)$, which was purified by acetylation to give Id $(\mathrm{R}=A \mathcal{Z}),\{\alpha\} \mathrm{D}^{-24.5^{\circ}}$ (c $1.3, \mathrm{CHCl}_{3}$ ).

The reductive fission of the $\beta$-chloro ether bonds with powdered sodium metal in the presence of ethylamine and THF afforded the crystalline ( $\left.8 R^{*}, 9 R^{*}\right)-d i o l$ 19 ( $R=H),\{\alpha\}+10.3^{\circ}\left(\mathrm{c} 0.8, \mathrm{CHCl}_{3}\right)$ in $96 \%$ yield (Ref. 23). Other reagents such as the zinc-silver couple (Ref. 24) or magnesium (ether, THF) were ineffective. The overall yield of $19,(R=H)$ from $16(R=H)$ was $74 \%$. The enantiomeric excesses of the new chiral compounds were established as $>95 \%$ by $1_{\mathrm{H}-\mathrm{NMR}}$ spectroscopy using chiral LISR for the acetates $16(\mathrm{R}=\mathrm{A} C)$, $18(R=A C)$ and $12,(R=A C) \mid$. Completion of the synthesis of $(E)-\gamma-b i$ sabolene$8\left(S^{*}\right), 9\left(R^{*}\right)$-epoxide $(2,0)$, which showed $\{\alpha\} D^{-68.8^{\circ}}$ (c $2.18, \mathrm{CHCl}_{3}$ ) lit (Ref. 25) $\{\alpha\} \mathrm{D}^{+37.3^{\circ}}$ (c $\left.2.20, \mathrm{CHCl}_{3}\right)$ for the natural enantiomer proceeded by tosylation ( $\mathrm{p} . \mathrm{TsCl}, \mathrm{C}_{5} \mathrm{H}_{5} \mathrm{~N}$ ) of the diol $12,(\mathrm{R}=\mathrm{H})$ to yield the oily monotosyl-derivative 12 ( $R=T S$ ) which was converted to $2 \ell$ in $96 \%$ yield by treatment with aqueous potassium hydroxide in methanol.

\section{Scheme 5}

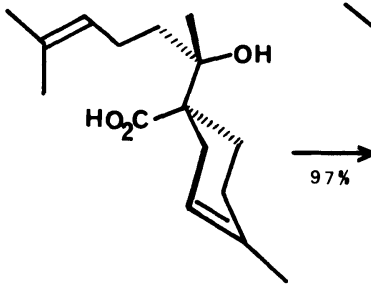

13

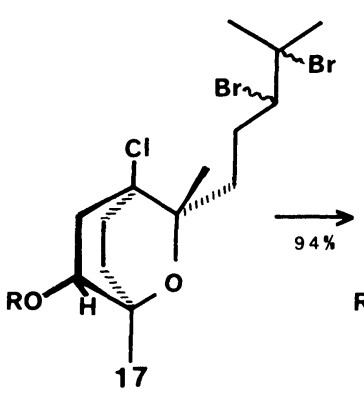<smiles>[Z17][C@]1(O)CC/C(=C(/C)CCC=C(C)C)C[C@@H]1Br</smiles>

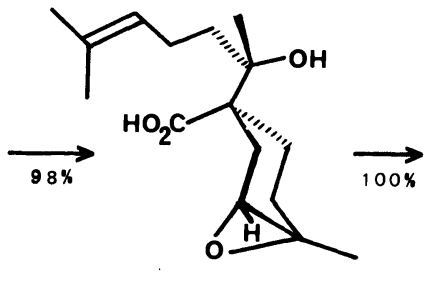

15

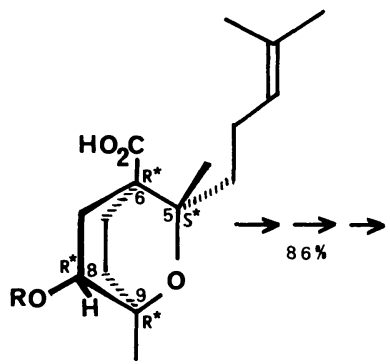

16
14

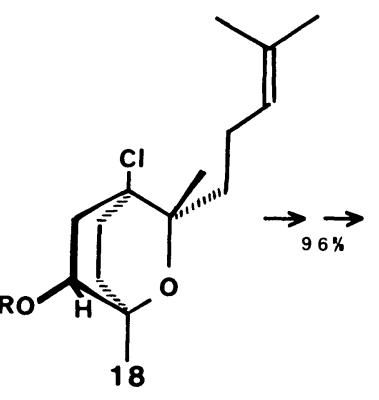<smiles>[R]O[C@@H]1CC(=C(C)CCC=C(C)C)CCC1(O)O</smiles><smiles>CCC1CC1C</smiles><smiles>CC(C)=CCC/C(C)=C1\CC[C@@]2([18O])O[C@H]2C1</smiles><smiles></smiles>

22<smiles>C=C1C[C@@H](O)[C@H](Br)C(C)(C)[C@]12CCC(C)(Br)[C@@H](Cl)C2</smiles> 


\section{SYNTHESES OF $(+) \beta$-CHAMIGRENE AND (2S, 6R)-2-BROMO- $\beta$-CHAMIGRENE}

Bromohydrin $(21),\{\alpha\}_{\mathrm{D}}^{22}+42.8\left(\mathrm{C} 1.16, \mathrm{CHCl}_{3}\right)$, was obtained in $94 \%$ yield by treatment (Ref. 26) of $2 \ell$ in THF with excess of dilithium tetrabromonickelate (II). The stereochemistry of 21 is clear from the $1_{H}$ NMR spectrum which unambiguously indicates that the bromomethine proton is axial: $\delta 4.05$ ( $d d, J=$ $11,4 \mathrm{~Hz}, 1 \mathrm{H}$ ). Brominative cyclization (Ref. 27) of 21 was effected using 1.5 equiv of $2,4,4,6$-tetrabromocyclohexa-2,5-diene in dry nitromethane at ambient temperature for $3 \mathrm{~h}$. The pure enantiomer $22,\{\alpha\}_{\mathrm{D}}+44.2$ (c $1.12, \mathrm{CHCl}_{3}$ ) was isolated as a non-crystalline solid from the crude reaction mixture by flash chromatography (Ref. 28). Treatment of 22 with $\mathrm{Zn}$-dust in acetic acid afforded in 838 yield the monobrominated diene $(2 S, 6 R)-2-$ bromo- $\beta$-chamigrene $(3),\{\alpha\}+13.5$ ( $\mathrm{c}_{1.12}, \mathrm{CHCl}_{3}$ ) | lit. (Ref. 8a) $\{\alpha\} \mathrm{D}+14$ (c $2.46, \mathrm{CHCl}_{3}$ ) for the

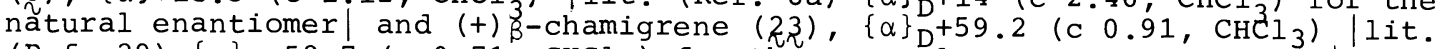
(Ref. 29) $\{\alpha\} \mathrm{D}^{-52.7}\left(\mathrm{C} 0.71, \mathrm{CHCl}_{3}\right.$ ) for the natural opposite enantiomer|. To assure ourselves of the absolute configuration and optical rotation of 3 , we carried out its synthesis starting from the $L$. obtusa metabolite isoobtứsol (24) (Ref. 30). Reduction of 24 with $\mathrm{Zn}-\mathrm{AcO}$ in in ether at $0^{\circ} \mathrm{C}$ yielded the partially dehalogenated $25,\left\{\alpha^{2}\right\} 22+82.1\left(\mathrm{c} 0.84, \mathrm{CHCl}_{3}\right.$ ), which was further transformed into $3,\{\alpha\} 2^{2}+14.4\left(\mathrm{C} 1.18, \mathrm{CHCl}_{3}\right)$ through the mesyl derivative 26 by treatment (Ref. 31) with lithium triethylborohydride in refluxing THF.

In the light of the foregoing effects predicted in scheme 3 , these results suggest that the cyclization of the bromohydrin 21 is not likely to occur from the form of the conformer $\lambda k$ due to its exclusive existence in the form of the conformer $7 \mathrm{~d}$.

Neighboring group participation (Ref. 32) is an established tool for reactivity control. It has been used for stereoselective introduction of functional groups (Ref. 33), selective protection (Ref. 34), double-bond transposition (Ref. 35), and to induce molecular conformational changes (Ref. 36). The chamigrene skeleton is synthesized here with regio- and stereocontrol by using simple forms of bridged intermediates.

Although quaternary carbon centers are challenging structural components of many complex natural compounds (Ref. 37), only a few methods for generating this moiety in an efficient enantioselective manner exist to date (Ref. 38). The results described here represent an effective procedure for construction of spiro|5.5| undecane systems containing a chiral quaternary center. This approach should be generally useful for the preparation of a wide variety of six-membered spirocarbocyclic containing natural compounds, and we are actively pursuing the scope and limitations of this asymetric methodology.

\section{TETRONIC ACID SESTERTERPENES FROM IRCINIA: SYNTHETHIC APPROACH}

Sesterterpenes are a rare group of natural products, but they are often encountered as secondary metabolites in sponges of the order Dictyoceratida (Ref. 39). The genus Ircinia has yielded a group of closely related linear sesterterpenes characterized by a $\beta$-substituted furan and tetronic acid ring as terminal units, the most unusual of which are the bicarbocyclic ircinianin (30) (Ref. 40) and wistarin ( 31 ) (Ref. 41), both isolated from I. wistarii, which appears to be the result of a $|4+2|$ cycloaddition of suitably unsaturated linear precursors (Scheme 6 ).

The remarkable biological activities of tetronic acid sesterterpenes make them attractive targets for synthesis. Our strategy for total syntheses of these compounds envisions completion of the $\mathrm{C}_{25}$ skeleton from independent syntheses and connection of the A-D synthons (Scheme 7) permitting a differentiated synthesis of the compounds by means of a common synthetic strategy. The target molecules in these preliminary synthetic studies were the antibiotics variabilin (27) (Ref. 42) and strobilinin (28) (Ref. 43) that present moreover the unsolved structural problem of the stereochemistry of their double bonds (Scheme 6).

\section{Synthetic approaches to 4-ylidene-tetronic acids}

Several methods of preparation of $\alpha, \beta$-butenolide and tetronic acid moieties have recently been published (Ref. 44-48). For the synthesis of the target 3-methyl-4-methoxy-5H-furan-2-one $(34)$ we have followed the previously described method of rearrangements of the appropriate $\beta$-keto esters (Ref. 49) with the modifications and yields indicated in scheme 8 , followed by methylation with dimethyl sulphate in base to give 35 (Ref. 50). 


\section{Scheme 6}<smiles>CC(=CCCc1ccoc1)CCC=C(C)CCCC(C)C=C1OC(=O)C(C)=C1O</smiles>

27<smiles>CC1=C[C@H](/C=C(\C)CCCc2ccoc2)[C@@]2(OC(=O)C(C)=C2O)[C@H]2[C@H](C)CC[C@@H]12</smiles><smiles>CC(=CCCC(C)C=C1OC(=O)C(C)=C1O)CCC=C(C)CCCc1ccoc1</smiles>

28

Wistarin<smiles>CC1=C[C@H]2C[C@](C)(CCCc3ccoc3)OC3=C(C)C(=O)O[C@]2([C@H]1C)[C@@H]1[C@@H](C)CC[C@@H]31</smiles><smiles>CC(=CC=CC(C)CCCC(C)C=C1OC(=O)C(C)=C1O)CCCc1ccoc1</smiles>

Linear furanoid sesterterpenes in Ircinia. Asterisk indicates that stereochemistry of olefin is unknown.

Scheme 7<smiles>Cc1ccoc1</smiles>

(A)<smiles>CC=C(C)CCC=C(C)CC</smiles>

(B)<smiles>CC(C)C</smiles>

(C)<smiles>CC1=C(O)COC1=O</smiles>

(D)

Despite the fact that the synthesis of $\alpha$-alkyliden- $\gamma$-butyrolactones by means of Wittig olefin syntheses is well documented (Ref. 51-53), bromination of compound 3,5 by any of the methods described led to an unstable and difficult to separate mixture of bromo-derivatives 36 and 37 . Treatment of monobrominated $3 k$ with triphenylphosphine gave the salt 3 \& that decomposed upon formation. In our hands the conversion $35 \rightarrow 36 \rightarrow 38$ evolved in a totally different manner, with results that differed from those published (Ref. 54). other alternatives to the synthesis of 4-ylidene-butenolides and 4-ylidene tetronic acids published recently include condensation of phosphoranes with alkyl-maleic anhydride (Ref. 55), dehydration or dealkoxylation of the<smiles>CCOC(=O)C(C)C(C)=O</smiles>

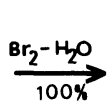<smiles>CCOC(=O)C(C)(Br)C(C)=O</smiles>

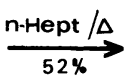<smiles>CC1=C(O)COC1=O</smiles>

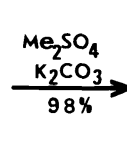<smiles>COC1=C(C)C(=O)OC1</smiles> 
reaction products of ketones with trimethylsilyloxyfuran (Ref. 56) or 2-trimethylsilyloxy-4-methoxyfuran (Ref. 57). Directed metallations of 0-alkyl tetronic acids with lithium diisopropylamide (LDA) in tetrahydrofuran (THF) followed by treatment at $-78^{\circ} \mathrm{C}$ with ketones in THF and dehydration proved to be a preparatively useful procedure for the synthesis of the corresponding $\alpha$-substituted O-methyl tetronic acids (Ref. 58, 59). Reaction of 35 with LDA at $-78^{\circ} \mathrm{C}$ in THF-HMPT followed by addition of $\mathrm{D}_{2} \mathrm{O}$ gave O-methyl 5-deuteriotetronate in $82 \%$ yield, hence anion 39 was formed and reacted at $\mathrm{C}-5$ in the fashion required. The reaction of $32^{2}$ with isobutyraldehyde gave 40 ( $\left.R=H\right)$ as a mixture of threo- and erythro-isomers in $70 \%$ yield, which were separated by fractional crystallization. Both compounds were independently converted into the same elimination product in high yield ( $90 \%$ ) through their corresponding

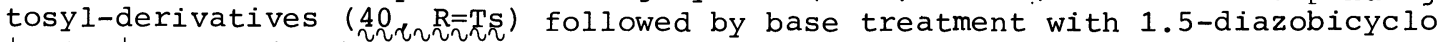
|4.3.0|nonene (DBN) at r.t. in ether or THF. The structure 41 for the single elimination product is tentative with respect to the stereochemistry of the double bond introduced, but it seems to be the most probable on the basis of similar previously reported studies (Ref. 60).<smiles>COC1=C(C)C(=O)OC1Br</smiles>

36<smiles>[R20][C@H](C(C)C)[C@H]1OC(=O)C(C)=C1C</smiles>

$40 a$<smiles>CC1=C(CBr)C(=O)OC1Br</smiles>

37<smiles>COC1=C(C)C(=O)OC1(Br)Br</smiles>

38<smiles>[CH]C1OC(=O)C(C)=C1OC</smiles>

39<smiles>[R20]C(C)C(C)[C@H]1OC(=O)C(C)=C1C</smiles>

$40 b$<smiles>COC1=C(C)C(=O)O/C1=C\C(C)C</smiles>

41

The appropriate aldehyde for our synthetic study (44) was prepared from the $\alpha$-methylacrylaldehyde $(42)$ by condensation with p-toluenesulfinic acid ( 43$)$, prepared in situ from the sodium salt (Ref.61).<smiles>C=C(C)C[CH+]c1ccc(S(=O)(=O)O)cc1</smiles>

42

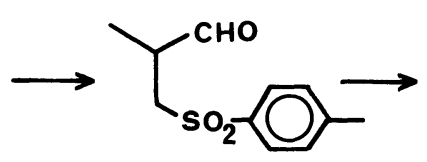

44<smiles>Cc1ccc(OS(=O)(=O)CC(C)C2OCCO2)cc1</smiles>

45

\section{Bifunctional isoprenoid synthesis}

The stereoselective synthesis of the polyenic isoprenoid 54 required for the synthesis of both variabilin (27) and strobilinin (28) was achieved following the classic works of M. Julia Ref. 62-65) and W. S. Johnson (Ref. 66) (Scheme 9).

Until now only timid attempts have been made to interconnect the prepared intermediates and the yields obtained have not been optimized. Despite the extensive literature available, the final synthetic result put forward here will depend on how the alkylations proposed for the already prepared synthons develop in our hands.

\section{Acknowledgements}

Support of this work by the CAICYT through Project 0153-81 is gratefully acknowledged (J.D.M.). J.M.P. and J.L.R. thank the Spanish Ministry of Education and Science for "Formation of Research Personnel" fellowships. We are grateful to Manuel de Leon Santana and Juan Antonio Suarez Gil, CSIC technical personnel, for running the NMR and MS spectra, respectively. Thanks are given to the pharmaceutical firm Madaus, S.A. (Cologne) and the Madaus Cerafarm Laboratories, S.A. (Barcelona) for carrying out pharmacological studies on the molecules investigated in this project. We also thank Pauline Agnew for helping with the translation and for preparing the manuscript, making its reading in English possible. 
Scheme 9<smiles>CC(=O)C1CCOC1=O</smiles>

46<smiles>CC(=O)C1(C)CCOC1=O</smiles>

47<smiles>CC(CCCl)C(=O)C1CC1[C@H](C)O</smiles>

48

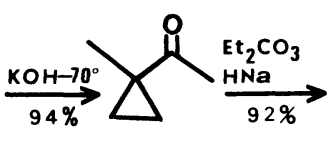

49<smiles>CCOCCC(=O)C1(C)CC1</smiles>

50

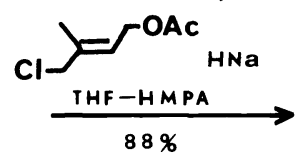

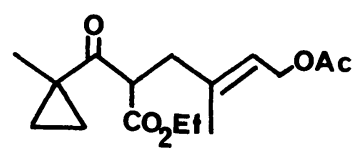

1) $\mathrm{Ba}(\mathrm{OH})_{2}-\mathrm{EtOH}-\mathrm{H}_{2} \mathrm{O}$ 2) $\mathrm{Ac}_{2} \mathrm{O}-\mathrm{PY}_{\mathrm{Y}}$

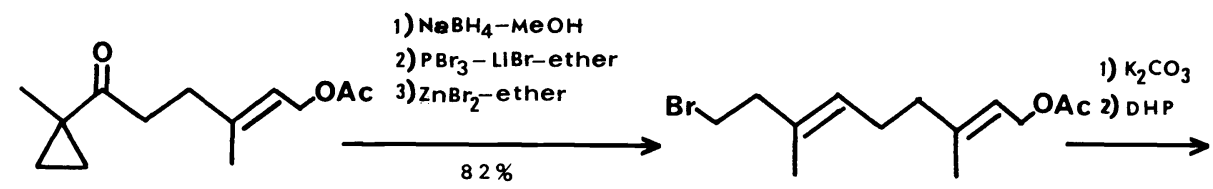

52

53<smiles>CC(=CCCC(C)=CCO[OH+])CCBr</smiles>

54

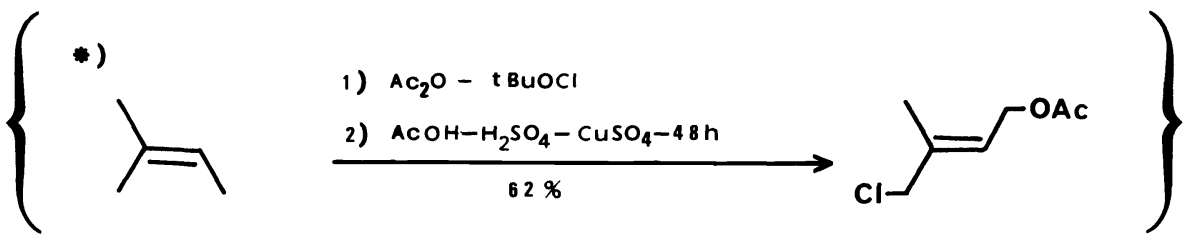

\section{REFERENCES}

1. D.J. Faulkner, Tetrahedron 33, 1421-1443 (1977); J.D. MartIn and J. Darias, in Marine Natural Products (Ed. P.J. Scheuer) Vol. 1, 125-173, Academic Press, New York (1978); $W$. Fenical, in Topics in the Biochemistry of Natural products (Ed. G.R. Waller) Vol. 13, 219-239, Plenum Press, New York (1979); K.L. Erickson, in Marine Natural products (Ed. P.J. Scheuer) Vol. 5, 131-258, Academic Press, New York (1983); D.J. Faulkner, Nat. Prod. Rep. 1, 251-280 (1984).

2. (a) M. Suzuki, A. Furusaki and E. Kurosawa, Tetrahedron 35, 823-831 (1979); (b) A.G. González, J.D. Martın, V.S. Martın, M. Norte and R. Perez, Tetrahedron Lett. 2395-2398 (1982); (c) M. Suzuki, M. Segawa, T. Suzuki and E. Kurosawa, Bull. Chem. Soc. Jpn. 56, 3824-3826 (1983).

3. For recent synthetic approaches see: (a) P.A. Krapcho, Synthesis 77-126 (1978); (b) E.R. Koft and A.B. Smith III, J. Org. Chem. 49, 832-836 (1984): (c) L.A. Paquette, T.-H. Yan and G.J. Wells, J. Org. Chem. 49, 3610-3617 (1984); (d) J. Shimada, K. Hashimoto, B.H. Kim, E. Nakamura and I. Kuwajima, J. Am. Chem. Soc. 106, 1759-1773 (1984) .

4. (a) A. Tanaka, M. Uda and A. Yoshikoshi, J. Chem Soc. Chem. Comm. 188-189 (1967); (b) T. Kato, S. Kanno and Y. Kitahara, Tetrahedron 26, 4287-4292 (1970); (c) J. White, S. Torii and J. Nagomi, Tetrahedron Lett. 2879-2882 (1974); (d) G. Frater, Helv. Chim. Acta 60, 515-517 (1977); (e) C. Iwata, 1.1. Yamada and Y. Shinoo, Chem Pharm. Bul1. 27, 274-275 (1979); (f) J.D. White, J.F. Ruppert, i1.A. Avery, S. Torii and J. Nokami, J. Am. Chem. Soc. 103, 1813-1821 (1981); (g) C. Iwata, K. Miyashita, Y. Koga, Y. Shinoo, M. Yamada and T. Tanaka, Chem. Pharm. Bull. 31, 2308-2312 (1983). 
5. Y. Ohta and Y. Hirose, Tetrahedron Lett. 2483-2486 (1968). For the absolute stereochemistry of 1 see Ref. $2 \mathrm{a}$.

6. (a) D.J. Faulkner, Pure and Appl. Chem. 48, 25-28 (1976); (b) L.E. Wolinsky and D.J. Faulkner, J. Org. Chem. 41, 597-600 (1976); (c) I. Ichinose and T. Kato, Chemistry Lett. 61-62 (1979).

7. B.M. Howard and W. Fenical, Tetrahedron Lett. 2519-2520 (1976). For the absolute stereochemistry of 2 see Ref. $2 a$.

8. (a) R.R. Izac, PhD Dissertation, Univ. California, Riverside (1978); (b) J.J. Sims, A.F. Rose and R.R. Izac, in Marine Natural Products (Ed. P.J. Scheuer) Vol. 2, 340, Academic Press, New York (1978).

9. E.E. van Tamelen, Acc. Chem. Res. 8, 152-158 (1975).

10. W.S. Johnson, Angew. Chem. Int. Ed. Engl. 15, 9-17 (1976); Bioorg. Chem. $5,51(1976)$.

11. E.J. Corey and K. Achiwa, Tetrahedron Lett. 2245-2246 (1970); Ibid, 32573258 (1969); E.J. Corey, K. Achiwa and J.A. Katzenellenbogen, J. Am. Chem. Soc. 91, 4318-4320 (1969); E.J. Corey, W.E. Russey and P.R. Ortiz de Montellano, Ibid 88, 4750-4751 (1966).

12. For more recent reviews see: (a) J.K. Sutherland, in Stereoselective Synthesis of Natural Products, Proceeding of the Seventh Workshop Conference, Hoechst, Schloss Reisensburg, 24-27, September 1978 (Eds. W. Bartmann and E. Winterfeldt), Excerpta Media, Amsterdam-Oxford, pp 142-150 (1979); (b) M. Matsuki, M. Kodama and S. Ito, Tetrahedron Lett. 2901-2904 (1979); (c) Y. Yamada, S. Nakamura, K. Iguchi and K. Hosaka, Tetrahedron Lett. 1355-

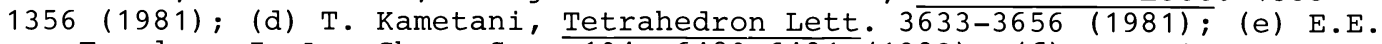

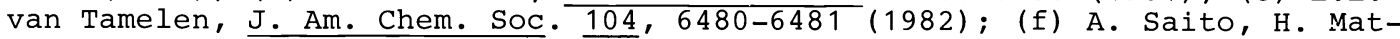
sushita and H. Kaneko, Chemistry Lett. $729-732$ (1983); (g) M. Nishizawa, H. Takenaka, H. Nishide and Y. Hayashi, Tetrahedron Lett. 2581-2584 (1983); (h) M.J.S. Dewar and C.H. Reynolds, J. Am. Chem. Soc. 106, 1744-1750 (1984); (i) M.D. Erion and J.E. McMurry, Tetrahedron Lett. 559-562 (1985).

13. (a) E.E. van Tamelen and E.J. Hessler, J. Chem. Soc. Chem. Comm. 411-412 (1966); (b) J.M. Greenwood, M.D. Salomon, J.K. Sutherland and A. Torre, J. Chem. Soc (c) 3004-3008 (1968); (c) A.G. González, J.D. Martín, C. Pérez and M.A. Ramirez, Tetrahedron Lett. 137-138 (1976); (d) L.E. Wolinsky and D.J. Faulkner, J. Org. Chem. 41, 597-600 (1976); (e) T.R. Hoye and M.A. Kurth, J. Org. Chem. 43, 3693-3697 (1978).

14. (a) T. Kato, I. Ichinose, S. Kumazawa and Y. Kitahara, Bioorg. Chem. 4 , 188-190 (1975); (b) T. Kato, I. Ichinose, A. Kamoshida and Y. Kitahará, J. Chem Soc. Chem. Comm. 518-519 (1976); (c) I. Ichinose and T. Kato, Chemistry Lett. 61-62 (1978); (d) H.M. Shieh and G. Prestwich, Tetrahedron Lett. 4643-4646 (1982); (e) Y. Yamaguchi, T. Uyehara and T. Kato, Tetrahedron Lett. 343-346 (1985).

15. (a) A. Murai, A. Abiko, K. Kato and T. Masamune, Chemistry Lett. 1125-1128 (1981); (b) A. Murai, K. Kato and T. Masamune, Tetrahedron Lett. 2887-2890 (1982); (c) A. Murai, A. Abiko and T. Masamune, Tetrahedron Lett. 4955$4958(1984)$.

16. (a) T.R. Hoye and M.J. Kurth, J. Org. Chem. 44, 3461-3467 (1979); (b) T.R. Hoye and M.J. Kurth, J. Am. Chem. Soc. 101, 5065-5067 (1979); (c) J.D. White, T. Nishiguchi and R.W. Skeen, J. Am. Chem. Soc. 104, 3923-3928 (1982); (d) T.R. Hoye, A.J. Caruso, J.F. Dellaria, Jr, and M.J. Kurth, J. Am. Chem. Soc. 104, 6704-6709 (1982); (e) M. Nishizawa, H. Takenaka, H. Hirotsu and Y. Hayashi, J. Am. Chem. Soc. 106, 4290-4291 (1984); (f) M. Nishizawa, H. Takenaka and Y. Hayashi, J. Am. Chem. Soc. 107, 522-523 (1985).

17. R.E. Ireland, M.I. Dawson, J. Bordner and R.E. Dickerson, J. Am. Chem. Soc. 92, 2568-2570 (1970); R.E. Ireland, M.I. Dawson, C.J. Kowalski, C.A. Lipinski, D.R. Marshall, J.W. Tilley, J. Bordner and B.L. Trus, J. Org. Chem. 40, 973-1000 (1975); R.E. Ireland, P. Bey, K.-F. Cheng, R.J. C Carny, J.-F. Moser and R.I. Trust, Ibid. 40, 1000-1007 (1975); R.E. Ireland, T.C. Mckenzie and R.I. Trust, Ibid 40, 1007-1017 (1975).

18. J.D. Martín, C. Pérez and J.L. Ravelo, J. Am. Chem. Soc. 107, 516-518 (1985).

19. L.E. Volinsky, D.J. Faulkner, J. Finer and J. Clardy, J. Org. Chem. 41, 697-699(1976).

20. Satisfactory IR, ${ }^{1}$ HNMR, ${ }^{13}$ CNMR and mass spectral data were obtained for each synthetic intermediate by using purified and chromatographically homogeneous samples. All chemical reactions were conducted under an inert atmosphere.

21. The acid $16(\mathrm{R}=\mathrm{Ac})$ was recovered quantitatively from the salt by treatment with $6 \mathrm{~N}$ hydrochloric acid in ether, washing with a small amount of saturated $\mathrm{Na}_{2} \mathrm{SO}_{4}$, and evaporation of ether. 
22. K.B. Becker, M. Geisel, C.A. Grob and F. Kuhnen, Synthesis 493 (1973).

23. For trans-elimination of $\beta$-halo-ethers sim-lar to that described in this manuscript, see: R.H. Schlessinger and R.A. Nugent, J. Am Chem. Soc. 104, $1116-1118(1982)$.

24. (a) T. Tokoroyama, K. Matsuo and R. Karazawa, Bull. Chem. Soc. Jpn. 53, 3383-3385 (1980); (b) G.A. Krans, B. Roth, K. Frazier and M. Shimagaki, J. Am. Chem. Soc. 104, 1114-1116 (1982); (c) W.R. Roush and T.E. D'Ambra, J. Am. Chem. Soc. 105, 1058-1060 (1983) .

25. Isolation and structure of (E)- $\gamma$-bisabolene-8,9-epoxide, see: T. Suzuki, H. Kikuchi and E. Kurosawa, Chemistry Lett. 1267-1270 (1980).

26. R.D. Dawe, T.F. Molinsky and J.V. Turner, Tetrahedron Lett. 2061-2064 $(1984)$.

27. (a) T. Kato, I. Ichinose, A. Kamoshida and Y. Kitahara, J. Chem. Soc. Chem. Comm. 518-519 (1976); (b) Y. Kitahara, T. Kato and I. Ichinose, Chemistry Lett. 283-286 (1976).

28. The yield (unoptimized) of pure 22 was only $17 \%$, but we could find no evidence of the presence of any other diastereoisomer in the crude cyclization product. The HNMR spectrum of 22 clearly indicates the axial stereochemistry of the bromomethine protons: $\delta 4.46(1 \mathrm{H}, \mathrm{dd}, \mathrm{J}=12.5,4.5 \mathrm{~Hz})$ and $4.54(1 \mathrm{H}, \mathrm{dd}, \mathrm{J}=13.5 \mathrm{~Hz})$.

29. Isolation and structure of (-) B-chamigrene found from the leaves of Chamaecyparis taiwanensis: S. Ito, K. Endo, T. Yoshida, M. Yatagai and M. Kodama, J. Chem. Soc. Chem. Comm. 186-188 (1967). For a recent racemic synthesis see: R.E. Ireland, W.C. Dow, J.D. Godfrey and S. Thaisrivong, J. Org. Chem. 49, 1001-1013 (1984).

30. A.G. González, J.D. Martín, V.S. Martín, M. Martínez-Ripoll and J. Fayos, Tetrahedron Lett. 2717-2718 (1979).

31. S. Krishnamurthy and H.C. Brown, J. Org. Chem. 41, 3064-3066 (1976).

32. (a) P.B.D. De la Mare, in Electrophilic Additions to Unsaturated Systems, Elsevier, Amsterdam (1982); (b) B. Capon and S.P. McManus, in Neighbouring Group Participation, Vol. 1, Plenum Press, New York (1976); (c) D.N. Kirk and M.P. Hartshorn, in Steroid Reaction Mechanisms, Elsevier, Amsterdam $(1968)$.

33. P. Rocovský, Tetrahedron Lett. 555-558 (1980); P.A. Bartlett, Tetrahedron $36,3-72(1980)$.

34. E.J. Corey and H.L. Pierce, J. Am. Chem. Soc. 101, 5841-5843 (1979).

35. S. Danishefsky, P.I. Schuda, T. Kitahara and S.J.'Etheredge, J. Am. Chem. Soc. 99, 6066-6075 (1977).

36. R.B. Woodward, F.E. Hader, H. Bickel, A.J. Frey and R.W. Kierstead, Tetrahedron 2, 1-57 (1958); I. Fleming and P.J. Michael, J. Chem. Soc. Chem. Comm. $2 \overline{9} 3-294$ (1977).

37. For an excellent review see: S.F. Martin, Tetrahedron 36, 419-460 (1980).

38. (a) Asymmetric C-C bond forming reactions from disubstituted $\mathrm{sp}^{2}$ carbon centers: H. Kogen, K. Tomioka, S. Hashimoto and K. Koga, Tetrahedron 37, 3951-3956 (1981); G.H. Posner, T.P. Kogan and M. Hulce, Tetrahedron Lett. 383-386 (1984); (b) Enantiotopic group differentiation from prochiral precursors bearing quaternary carbon centers (chemical or enzymatic methods): Z.G. Hajos and D.R. Parrish, J. Org. Chem. 39, 1615-1621 (1974); D.W. Brooks, P.G. Grothans and W.L. Irwing, J. Org. Chem. 47, 2820-2821 (1974); M. Schneider, N. Engel and H. Boensmann, Angew Chem. Int. Ed. Engl. 23, 66 (1984); (c) Asymmetric C-C bond forming reactions from ternary carbon centers: S. Yamada and G. Otani, Tetrahedron Lett. 4237-4240 (1969); B. Langström and G. Bergson, Acta Chem. Scand. 27, 3118-3119 (1973); H. Wynberg and R. Helder, Tetrahedron Lett. 4057-4 $\overline{06} 0$ (1975); S. Hashimoto and K. Koga, Tetrahedron Lett. 573-576 (1978); K. Hermann and H. Wynberg, J. Org. Chem. 44, 2238-2244 (1979); D.J. Cram and G.D.Y. Sogah J. Chem. SOC. Chem. Comm. $625-628$ (1981); D. Enders, Chem. Tech. 11, $5045 \overline{13}(1981)$; T. Hayashi, K. Kanehira, H. Tsuchiya and M. Kumada, J. Chem Soc. Chem. Comm. 1162-1164 (1982); U.H. Dolling, P. Davis and E.J.J. Grabowski, J.A.m. Chem. Soc. 106, 446-447 (1984); A.I. Meyers, M. Harre and R. Garland, J. Am. Chem. Soc. 106, 1146-1148 (1984); K. Tomioka, K. Ando, K. Takemasa and K. Koga, J. Am. Chem. Soc. 106, 2718-2719 (1984); D.F. Taber, E.H. Petty and K. Raman, J. Am. Chem. Soc. 107, 196-199 (1985); M. Pfau, G. Revial, A. Guingant an $\overline{\mathrm{d}} \mathrm{J}$. d'Angelo, J. $\overline{\mathrm{Am}}$. Chem. Soc. 107, 273-274 (1985).

39. J.T. Baker and P. Murphy, in Compounds from Marine organisms, Vol. 1, 2, CRC Press, Cleveland (1976); L. Minale, G. Cimino, S. de Stefano and G. Sodano, Fortschr. Chem. Org. Naturstoffe 33, 1 (1976); D.J. Faulkner, Nat. Prod. Rep. 1, 551-598 (1984).

40. W. Hofheinz and Schönholzer, Helv. Chim. Acta 60, 1367-1370 (1977).

41. R.P. Gregson and D. Ouvrier, J. Nat. Prod. 45, $412-414$ (1982).

42 D.J. Faulkner, Tetrahedron Let $\overline{t .3821-3822}$ (1973). 
43. I. Rothberg and P. Shubiak, Tetrahedron Lett. 769-772 (1975).

44. J. Cardellach, C. Estopa, J. Font, N. Moreno-Mañas, R.M. Ortuño, F. Sanchez-Ferrando, S. Valle and L. Vilamajo, Tetrahedron 38, 2377-2394 (1982).

45. J. Erickson and P.E. Plith, Tetrahedron Lett. 481-484 (1982).

46. I. Kuwajima and H. Urabe, Tetrahedron Lett. 5191-5194 (1981).

47. K. Takeda, H. Kubo, T. Koizumi and E. Yoshii, Tetrahedron Lett. 3175-3178 (1982) .

48. H.D. Stachel and K. Dandl, Tetrahedron Lett. 2891-2892 (1980).

49. A. Svendsen and P.M. Boll, Tetrahedron 29, 4253-4258 (1973).

50. A.S. Wengel, T. Reffstrup and P.M. Boll, Tetrahedron 35, 2181-2185 (1979).

51. P.S. Steyn, w.J. Conradie, C.F. Garbers and M.J. de vries, J. Chem Soc. 3075-3079 (1965).

52. J.F. Blount, R.-J.L. Han, B.A. Pawson, R.G. Pitcher and T.M. Williams, $\mathrm{J}$. Org. Chem 41, 4108-4110 (1976).

53. J.E.T. Corrie, Tetrahedron Lett. 4873-4876 (1971).

54. D.W. Knight and G. Pattenden, J.C.S. Perkin I, 635-640 (1975).

55. D.W. Knight and G. Pattenden, J.C.S. Perkin I, 62-69 (1979).

56. M. Asaoka, N. Yanagida, K. Ishibashi and H. Takei, Tetrahedron Lett. 42694270 (1981).

57. A. Pelter, R. Al-Bayati and W. Lewis, Tetrahedron Lett. 353-356 (1982).

58. N.G. Clemo and G. Pattenden, Tetrahedron Lett. 581-584 (1982).

59. N.G. Clemo and G. Pattenden, Tetrahedron Lett. 585-588 (1982).

60. A. Pelter, M.T. Ayoub, J. Schultz, R. Hänsel and D. Reinhardt, Tetrahedron Lett. 1627-1630 (1979)

61. G.K. Cooper and L.J. Dolby, J. Org. Chem. 44, 3414-3416 (1979).

62. M. Julia, S. Julia and R. Guégan, Bull. Soc. Chim. France.1072-1079 (1960).

63. M. Julia, S. Julia and Y. Noël, Bull. Soc. Chim. France.1708-1711 (1960).

64. M. Julia, S. Julia and S.Y. Tchen, Bull. Soc. Chim. France. 1849-1853 $(1961)$.

65. M. Julia, S. Julia, T. Song Yu and C. Neuville, Bull. Soc. Chim. France. $1381-1385(1960)$.

66. S.F. Brady, M.A. Ilton and W.S. Johnson, J. Am. Chem. Soc. 90, 2882-2889 (1968) . 